\title{
EL JUEZ CONSTITUCIONAL COLOMBIANO \\ COMO LEGISLADOR POSITIVO: ¿UN GOBIERNO \\ DE LOS JUECES?
}

\section{COLOMBIAN CONSTITUTIONAL JUDGE AS THE POSITIVE LEGISLATOR: A GOVERNEMENT OF THE JUDGES?}

\author{
Germán Alfonso LóPEZ DAZA*
}

Resumen: La justicia constitucional en el mundo ha presentado una notable evolución y Colombia no ha sido ajena a esta tendencia global. Desde su entrada en funcionamiento en 1992, la Corte Constitucional colombiana ha sido protagonista del desarrollo de la carta de 1991, hasta tal punto que ha llegado a afectar notablemente, presupuestos básicos intocables del anterior régimen legal, como la seguridad jurídica. Bajo los postulados de la defensa de la Constitución, del Estado social de derecho y de los derechos fundamentales, la jurisprudencia del tribunal constitucional colombiano ha enfrentado decisiones tomadas por los otros poderes y por jueces y magistrados, lo que ha generado el apelativo de gobierno de los jueces.

Palabras claves: Justicia constitucional, Corte Constitucional, manipulación de sentencias, activismo judicial, legislador positivo, gobierno de los jueces.
ABSTRACT: The constitutional justice in the world has made a remarkable evolution and Colombia has not been immune to this global trend. Since coming into operation in 1992, the Colombian Constitutional Court has been a leader in the development of the Charter of 1991 to the point that has come to affect significantly basic assumptions of former untouchables legal, as legal certainty. Under the principles of defending the Constitution, the Rule of law and fundamental rights, the jurisprudence of the Colombian Constitutional Court decisions faced by the other powers and by judges and magistrates, which has led to the nickname of government of the judges.

Descriptors: Constitutional Justice, Constitutional Court, manipulation of statements, judicial activism, positive legislator, government of judges.

\footnotetext{
* Profesor e investigador de la Universidad Surcolombiana (Colombia).
} 


\section{INTRODUCCIÓN}

El constitucionalismo colombiano, desarrollado con el texto promulgado por la Asamblea Nacional Constituyente de 1991, ha venido generando importantes avances en el derecho colombiano.

El texto constitucional contiene gran cantidad de principios y reglas directamente aplicables a todo tipo de conflictos jurídicos que necesariamente deben aplicar los jueces, los funcionarios administrativos o los litigantes en Colombia.

Esta situación contrasta notablemente con la condición dogmática de la Constitución colombiana de 1886, donde el texto constitucional sólo podía ser directamente aplicado por los organismos vértices del Estado en asuntos de alta política. Así pues, el presidente de la República, el Congreso y la Corte Suprema de Justicia parecían ser los únicos actores legitimados (en situaciones muy especiales) para aplicar directamente el contenido del texto fundamental.

La Constitución de 1886 no conocía de mecanismos de aplicación generalizada, como la llamada excepción de inconstitucionalidad; de la misma manera, la acción pública de inconstitucionalidad era, sin duda, un recurso importante. Sin embargo, la jurisprudencia constitucional era escasa y limitada.

Dentro del concepto tradicional de Estado de derecho, los jueces entendían que su misión consistía en aplicar las reglas y principios enunciados por los códigos y las leyes; la Constitución se expresaba mediante la ley, suprimiendo así la necesidad de interpretar directamente el texto superior. Por ello, los niveles de constitucionalización del conflicto común eran muy vagos.

La Constitución de Colombia de 1991 varió los conceptos de constitucionalismo e instauró de manera inequívoca la idea de supremacía directa de la Constitución ${ }^{1}$ y la protección de los derechos constitucionales fundamentales de los ciudadanos, con argumentos basados en el texto constitucional sin intermediación legal. Los contenidos constitucionales se convierten en

1 La Corte Constitucional colombiana expresó desde sus inicios que la carta política de 1991 tenía un poder vinculante, es decir que esta era directamente aplicable, principalmente en los casos de protección de derechos fundamentales. Véase entre otras las sentencias T-406 de 1992 M.P. Ciro Angarita Barón, C-479 de 1992 M.P. José Gregorio Hernández Galindo y Alejandro Martínez Caballero, C-543 de 1992 M.P. José Gregorio Hernández Galindo, T-006 de 1992 M.P. Eduardo Cifuentes Muñoz, T-567 de 1992 M.P. Alejandro Martínez Caballero, Fabio Morón Díaz y José Gregorio Hernández. 
principios y reglas directamente aplicables a todo tipo de conflicto jurídico por resolver.

Muchos cambios importantes se han presentado en la última década en la teoría de las fuentes del derecho (ligando la aplicación directa de la Constitución a un nuevo uso de los precedentes judiciales), en la argumentación jurídica y en la forma de enfrentar o abordar el problema de las fuentes del derecho.

El juez constitucional (Corte Constitucional y jueces cuando conocen de acciones de tutela) por medio de su jurisprudencia, aparece como un creador consciente de sus reglas constitucionales y no como un simple aplicador pasivo de los textos superiores, democratizando de esta forma el uso de la Constitución.

Es en este contexto que el presente artículo pretende presentar un esbozo jurisprudencial de algunas decisiones judiciales de la Corte Constitucional colombiana desde la perspectiva de la técnica de la manipulación o modulación de los fallos para aproximarlo a la teoría del gobierno de los jueces.

En un primer momento se hará una breve descripción de los cambios introducidos por las decisiones de la Corte Constitucional, así como los enfrentamientos que estas decisiones han generado entre las diferentes ramas del poder público.

En un segundo momento se hará una breve descripción de las sentencias manipulativas, como un ejemplo claro del rompimiento de la clásica separación de poderes y configuración del Tribunal Constitucional colombiano en un verdadero legislador positivo.

Por último, se hará una aproximación a la construcción teórica del concepto "gobierno de los jueces" desarrollado por Edouard Lambert en 1921, su posible aplicación al caso colombiano y algunas posibles explicaciones desde la teoría actual.

\section{PRIMERA PARTE \\ El ACTIVISMO JUDICIAL DE LA CORTE CONSTITUCIONAL COLOMBIANA}

El magnífico desarrollo de la jurisprudencia de la Corte Constitucional colombiana ha generado un alto grado de aceptación entre la sociedad, debido a la protección ordenada en las sentencias de la Corte en materia de 
protección de los derechos fundamentales, derechos sociales y excepcionalmente derechos colectivos.

A la Corte Constitucional se le encomendó la importante misión de unificar la jurisprudencia mediante la revisión de las acciones de tutela e, igualmente, velar por la supremacía de la Constitución, por medio de los fallos de constitucionalidad. ${ }^{2}$

Esta vasta tarea impuesta a la Corte y desarrollada en buena forma en estos 20 años de funcionamiento, ha permitido desarrollar una extensa doctrina constitucional jurisprudencial, la que a su vez ha permitido construir unas bases sólidas sobre las cuales se ha venido edificando el constitucionalismo colombiano del siglo XXI.

La audacia de la Corte ha llegado a los extremos de atenuar la otrora rígida separación de poderes mediante la "modulación o manipulación"3 de sus fallos, bajo el argumento de que sólo ella puede dar el alcance a sus providencias. De igual forma, el alto tribunal constitucional colombiano se ha convertido en el último eslabón de la pirámide del poder público en Colombia. Cualquier controversia por banal que sea, es susceptible de constitucionalizarse y con ello la discusión no se puede considerar cerrada hasta tanto la Corte no se pronuncie sobre el asunto.

\section{El dinamismo de la Corte Constitucional colombiana:} hacia un sistema de precedente judicial

\section{A. Panorama del sistema americano}

A pesar de que el derecho de América Latina pertenece a la familia del derecho romano germánico, el modelo norteamericano fue adoptado por un

2 El artículo 241 de la Constitución Política colombiana establece las competencias de la Corte Constitucional. En dicha normativa, la carta de 1991 le confía a la Corte, la guarda de la integridad y supremacía de la Constitución. Para lograr tal fin, debe decidir sobre las demandas de inconstitucionalidad que instauren los ciudadanos o realizar dicho control de manera oficiosa, en los casos que precise la Constitución (control previo automático, control posterior automático y control por vía por vía de acción).

3 La manipulación o la modulación es una técnica de decisión judicial en la que el juez constitucional, evita la declaratoria de inconstitucionalidad de una norma legal transformando su significado y alcance. 
primer grupo de países de esta región, ${ }^{4}$ especialmente en lo que respecta al poder de los jueces ordinarios de dirimir conflictos de cuestión constitucional.

Un segundo grupo de países del América Latina no siguió el modelo norteamericano de control difuso, es decir, el de adoptar un sistema de control constitucional ejercido por cualquier juez. Fue el caso de Colombia, en donde se aprobó en la reforma de 1910 (introducida a la Constitución de 1886), un sistema de control constitucional concentrado en cabeza de un órgano judicial y que ejercería su labor de control por medio de una acción popular de inconstitucionalidad. Fue así como Colombia siguió un camino diferente al norteamericano.

Históricamente, la jurisprudencia estadounidense ha mostrado una actitud ambivalente con la idea de que los jueces pueden "legislar" siendo ésta una característica muy difundida. Las normas creadas judicialmente fueron, de hecho, las deducciones de un cuerpo preexistente de derecho común llamado principios. ${ }^{5}$ Sin embargo, a mediados del siglo XX, esta idea fue desbaratada y se hizo común la frase "judges do and must legíslate".

El acto de legislar fue completado en el momento en que los tribunales entraron en escena. Su trabajo consistía en aplicar la norma vigente a un conjunto particular de hechos. En este sentido, los jueces, a pesar de su independencia constitucionalmente reconocida, se percibían como la realización de una función ejecutora. ${ }^{6}$

Thomas Jefferson expresó este punto de vista cuando declaró que el juez debe ser una "simple máquina". 7 En el caso fundacional de Marbury vs.

4 Fueron los casos de la República Dominicana en 1844, de México en 1847, de Argentina en 1860 y de Brasil en 1891. Estos países adoptaron el modelo norteamericano de control constitucional por todos los jueces, tanto de los actos públicos como de las leyes. Cada país adoptó el sistema americano, pero le introdujo modalidades propias. Fue el caso por ejemplo de México y de la República de El Salvador en donde, inspirados en el recurso del hábeas corpus propio del common law, crearon el recurso de protección de derechos constitucionales que denominó derecho de amparo. Este recurso establecía que todo particular podría demandar ante una Corte federal, la protección de un derecho garantizado constitucionalmente, pudiendo el juez de la causa inaplicar una ley en caso de inconstitucionalidad.

5 Véase Brian Z. Tamanaha, Beyond the Formalist-Realist Divide: the Role of Politics in Judging, Princeton Univ. Press, 2009.

6 Véase Laurence Claus, Montesquieu's Mistakes and the True Meaning of Separation, 25, Oxford J. Legal

Stud. 2005, pp. 419, 421 y 423.

7 Thomas Jefferson, "Thomas Jefferson to Edmund Pendleton, August 26, 1776", en P. Boyd, Julián et al. (eds.), The Papers of Thomas Jefferson, 1950. 
Madison, ${ }^{8}$ el presidente del Tribunal Supremo, representó la anulación de una ley inconstitucional, no como un ejercicio discrecional de poder, sino como un ineludible deber u obligación. ${ }^{9}$

Los Estados Unidos ofrecen una visión muy especial de la creación judicial pues por antonomasia, es el imperio americano el que ofrece el mejor laboratorio debido a su common law. La cultura jurídica norteamericana se ha caracterizado desde sus inicios por se antiformalista y pragmática, al contrario de lo que acaece con la europea.

Esta influencia americana en el mundo latinoamericano y más precisamente en Colombia no se limita hoy día al estudio de Rawls o Dworkin. Dicha influencia ha generado que no se hable de un sistema romano-germánico. Estas diferencias de los sistemas jurídicos clásicos, anteriormente muy claras, hoy no lo son tanto. Muchos autores ${ }^{10}$ hablan de la progresiva convergencia de los dos sistemas, originando una hibridación o mixtura con características de ambas familias.

\section{B. Aproximación de Colombia al sistema del precedente}

La Corte estableción ${ }^{11}$ que el respeto a los precedentes cumple funciones esenciales en los ordenamientos jurídicos, incluso en los sistemas de derecho legislado como el colombiano. Por ello, la Corte, y en especial el juez constitucional, debe ser consistente con sus decisiones previas por cuatro razones: 1) por elementales consideraciones de seguridad jurídica y de coherencia del sistema jurídico; 2) para proteger la libertad ciudadana y permitir el desarrollo económico; 3 ) en virtud del principio de igualdad, puesto que no es justo que casos iguales sean resueltos de manera distinta por un mismo juez; 4) el respeto al precedente impone a los jueces una mínima racionalidad y universalidad, ya que los obliga a decidir el problema

8 Marbury vs. Madison, 5 U.S. (1 Cranch) 137 (1803).

9 Philip Hambuger ha subrayado recientemente la importancia histórica que han tenido los jueces por la obligación que tienen de controlar la ley, siendo esta situación común en la historia del desarrollo de la jurisdicción constitucional. Véase, Hamburger Philip, Law and Judicial Duty, 2008.

10 Véase principalmente Fernández Segado, Francisco, La justicia constitucional ante el siglo XXI: la progresiva convergencia de los sistemas americano y europeo continental, México, UNAM, 2004.

11 Corte Constitucional colombiana, sentencia SU-047 de 1999 M.P. Carlos Gaviria Díaz y Alejandro Martínez Caballero. 
que les es planteado de una manera que estarían dispuestos a aceptar en otro caso diferente pero que presente caracteres análogos.

La jurisprudencia de la Corte Constitucional amplió en forma extraordinaria su dominio de aplicación en el derecho, no sólo constitucional sino general. Anteriormente, bajo la Constitución de 1886, la jurisprudencia de la Corte Suprema de Justicia era aplicable solamente a ciertos niveles del Estado. Actualmente, los fallos de la Corte son aplicables en todos niveles: en la vida de los ciudadanos, en los litigios tratados por los abogados y, por supuesto, por los jueces. En todas las ramas del derecho debe necesariamente aplicarse el derecho constitucional jurisprudencial de la Corte.

El sistema colombiano de fuentes del derecho se ha aproximado al sistema americano, a pesar de su pertenencia al sistema romano-germánico o de la Europa continental. Tal aproximación por vía jurisprudencial, a pesar de existir taxativamente otro enfoque (artículo 230 de la CP), ha generado interrogantes como el de saber cuáles son los límites o las pautas que este tribunal debe observar, pues este parece tener la llave para salir airoso ante cualquier limitación que se le quiera crear.

\section{Justicia constitucional vs. Poder Ejecutivo-Poder Legislativo}

Las Constitución Política de Colombia tiene una orientación claramente finalista, es decir, su articulado buscó sentar las bases para la solución de muchos problemas consagrando una buena cantidad de principios y valores, muchos de ellos incumplidos (vida, paz, justicia social, solidaridad, trabajo para todos, etcétera). Esta sobrecarga de deseos ha provocado en algunos sectores, una alta dosis de escepticismo debido a su evidente incumplimiento después de casi 20 años de vigencia de la carta. ${ }^{12}$ Las anteriores críticas han acompañado muchas otras como la falta de cohe-

12 En Colombia existe la creencia equivocada de que todos los males que aquejan al país como la violencia, la corrupción, el desempleo, el déficit fiscal, el narcotráfico etcétera, se curan con reformas constitucionales o reglamentaciones legales. La falsa creencia de que los grandes problemas nacionales se resuelven con cambios normativos, casi siempre constitucionales, ha dejado un amargo sabor a lo largo de la historia política colombiana, porque si bien en ocasiones se requieren modificaciones de este tipo, no se puede caer en la ilusión de pensar que la norma por sí sola produce efectos mágicos en la realidad. Es lo que muchos han denominado con razón, fetichismo constitucional. Véase, entre otros, Vargas Velásquez, Alejo, Nueva prospectiva para la paz de Colombia, México, Red Convergencia, 2006, p 26. 
rencia en algunos de sus artículos, la ausencia de una ideología definida, la extrema amplitud de su articulado y su excesiva reglamentación así como las 28 reformas que en 20 años le han realizado.

Sin embargo, muchos sectores de la doctrina colombiana y la misma Corte Constitucional han expresado que la carta política debe ser considerada como un primer paso para el logro de una verdadera justicia social y para la protección de los derechos fundamentales. ${ }^{13}$

Esta protección es realizada por todos los jueces de la República, quienes por medio de la acción de tutela y de otras acciones constitucionales como el hábeas corpus o las acciones populares, protegen los derechos de los ciudadanos.

Los jueces colombianos tienen su propio ámbito de competencia: ellos imparten justicia, no gobiernan. Sin embargo, en muchas situaciones es posible que la protección de algún derecho o la búsqueda de la justicia, generen políticas públicas ante su inexistencia o vayan en contravía de las estas. En tales casos, se impone el Estado social de derecho.

El juez constitucional debe, ante todo, aplicar una cantidad de principios y reglas, ${ }^{14}$ desarrolladas ampliamente por la Corte Constitucional y buscar la justicia en los problemas que le son presentados para su solución. Esta misión obliga al juez a invadir, necesariamente, orbitas que teóricamente hablando en términos de Montesquieu, estarían fuera de su alcance.

Desde la promulgación de la Constitución de 1991 y más precisamente en 1992, año en que entró en funcionamiento la Corte Constitucional, han sido muchos los enfrentamientos del máximo tribunal constitucional con las otras ramas del poder público.

Periódicamente, el ciudadano del común se informa por medio de los medios de comunicación sobre los enfrentamientos entre las tres ramas del poder público o, en muchas ocasiones, entre los altos tribunales al interior de la misma rama judicial.

13 Así lo expresó la Corte Constitucional en las sentencias C-479 de 1992 y T-217 de 1994.

${ }^{14}$ La Corte Constitucional conceptualizó de manera clara y precisa, la diferencia entre los principios y valores y la forma como debían ser aplicados en un Estado Social de Derecho, en la sentencia T-406 de 1992 M.P. Ciro Angarita Barón. 
Si se observan estos enfrentamientos institucionales o choques de trenes ${ }^{15}$ (como periodísticamente se les ha llamado), es posible establecer cuatro situaciones que los puede generar:

Por los fallos proferidos por todos los jueces con ocasión de las acciones de tutela y, principalmente, los pronunciamientos de la Corte Constitucional contra las autoridades administrativas, debido a la violación de derechos fundamentales.

Por las sentencias de acciones de tutela proferidas por los jueces y, en especial, por la Corte Constitucional, contra los fallos de otros jueces o altos tribunales (Consejo de Estado, Corte Suprema de Justicia, Consejo Superior de la Judicatura) mediante la aplicación de la teoría de la vía de hecho.

Por las decisiones emitidas por la Corte Constitucional a raíz de las acciones de inconstitucionalidad de leyes o decretos especiales, que afectan principal y directamente al ejecutivo.

Por las providencias de la Corte Constitucional mediante las cuales se le sugiere (o en ocasiones se le ordena) al Congreso de la República actuar en determinado sentido, ante la inactividad legislativa o para remediar vacíos o lagunas normativas. Fallos como el de la inconstitucionalidad del Concordato suscrito entre Colombia y la Santa Sede, ${ }^{16}$ la despenalización del consumo de la dosis personal, ${ }^{17}$ la legalización de la eutanasia, ${ }^{18}$ la protección del derecho a la inviolabilidad parlamentaria de los congresistas, ${ }^{19}$ la inconstitucionalidad de la prohibición de aumento de salarios de los funcionarios del Estado, ${ }^{20}$ la misma despenalización del aborto en Colombia ${ }^{21}$ y más recientemente la

15 Sobre este tema es abundante la doctrina colombiana. Consúltense entre otros los siguientes artículos: Gómez García, Carlos Fernando, "Las vías de hecho como generadoras del choque de trenes en la jurisprudencia constitucional. (1992-2008)", http:// criteriojuridico.puj.edu.co/; Henao Orozco, Rubén Darío, "Tutela contra sentencias de las altas Cortes o choque de vanidades", http://www.iidpc.org/pdf/ajr6HenaoOrozco.pdf; "El choque de trenes" o las Contradicciones entre las Altas Cortes del Poder Judicial", Crítica Política, núm. 146, http://escuelajuridica.org; Giraldo Ángel, Jaime, "El choque de trenes. Sobre los sistemas de interpretación jurídica en Colombia", http://www.tribu nales.colpsic.org.co/documentos/Giraldo_CDT.pdf, entre muchos otros.

16 Sentencia C-027 de 1993 M.P. Simón Rodriguez Rodriguez.

17 Sentencia C-221 de 1994 M.P. Carlos Gaviria Díaz.

18 Sentencia C-239 de 1997 M.P. Carlos Gaviria Díaz.

19 Sentencia SU-047 de 1999 M.P. Carlos Gaviria Díaz y Alejandro Martínez Caballero.

20 Sentencia 1433 de 2000 M.P. Antonio Barrera Carbonell.

21 Sentencia C-355 de 2006 M.P. Jaime Araujo Rentería y Clara Inés Vargas. 
inconstitucionalidad de una reforma constitucional por vicios de fondo, ${ }^{22}$ han originado una avalancha de críticas por el desmesurado protagonismo. En muchas sentencias de constitucionalidad, la Corte ha manipulado sus decisiones lo que ha avivado el debate sobre la extralimitación de sus funciones y ha generado la acusación de que Colombia haya pasado a tener un gobierno de los jueces.

\section{La Corte Constitucional colombiana como legislador positivo}

El control desplegado por la Corte Constitucional colombiana le ha generado numerosas críticas, entre otras cosas por las modificaciones efectuadas a las leyes por medio de las cuales, ordena la imposición de un efecto no previsto por el legislador. Los críticos consideran que la Corte invade los campos del legislativo y que ella contribuye a crear un clima de inseguridad jurídica. ${ }^{23}$

El ejercicio del control constitucional de la leyes hecho por la Corte Constitucional ha conducido a este tribunal a proferir diferentes tipos de sentencia de constitucionalidad. El soporte de estas providencias se encuentra en la teoría kelseniana del legislador negativo. ${ }^{24}$

22 Sentencia C-588 de 2009 M.P. Gabriel Eduardo Mendoza Martelo.

23 Reconocidos constitucionalistas colombianos como Luis Carlos Sáchica e Iván Vila Casado entre muchos otros, critican abiertamente las actuaciones judiciales de la Corte Constitucional por extralimitarse en sus funciones. El primero la cataloga como una "Corte Constitucional bizca" o que padece estrabismo pues la acusa de hacer con un ojo guiños a la política y con el otro, fija su mirada en su jurisprudencia petrificada (Ámbito Jurídico, 15 al 26 de marzo de 2010). Vila Casado por su lado la acusa de haber "brincado la cerca" pues ella se abrogó competencias no contempladas en el artículo 241 de la Constitución, cuando declaró inconstitucional una reforma constitucional aprobada por el Congreso colombiano por vicios de fondo, siendo su competencia la revisión por vicios de procedimiento o de forma (Ámbito Jurídico, septiembre de 2009).

${ }^{24}$ Kelsen propone la creación de un tribunal especializado e independiente de los poderes públicos tradicionales teniendo en cuenta los temas que debe abordar (supremacía de la Constitución). Cuando habla de "legislador en sentido negativo" lo hace pensando en el caso americano y para el supuesto austriaco. Dijo Kelsen: "Un tribunal facultado para anular leyes - en forma individual o de manera general - funciona como un legislador en sentido negativo". Cit. por Pérez Tremps, Pablo, Madird, Tribunal Constitucional y Poder Judicial-CEC, 1981, pp. 6 y ss. La cita de Kelsen está en Kelsen, Hans, Teoría general del derecho y del Estado, trad. de García Máynez, México. UNAM, 1979, pp. 303-334. 
Hans Kelsen defendió la existencia de los tribunales constitucionales, ${ }^{25}$ con la necesidad de asegurar la supremacía de la Constitución y la regularidad de la normatividad en vigencia. El jurista vienés afirmó que una Constitución sin garantía de anulación de los actos inconstitucionales, no es una Constitución completamente obligatoria. ${ }^{26}$

Es por esto que Kelsen concibe el tribunal constitucional como legislador negativo; el parlamento ejerce la función de dictar las leyes (legislador positivo) y el juez constitucional ejerce la función de anularlas cuando sean contrarias a la Constitución.

Kelsen distingue entre la elaboración de la ley (función del parlamento) y su anulación (función del tribunal constitucional). La primera función es la facultad de libre creación del parlamento y la segunda (legislador negativo) está contenida en la Constitución.

Por razones de seguridad jurídica, la decisión proferida por el juez constitucional no tendría ningún efecto retroactivo y sería obligatoria a partir de su publicación. Sin embargo, existe una restricción muy importante: los tribunales constitucionales no pueden crear normas jurídicas positivas debido al principio de separación de poderes. Si lo hacen, invadirían las competencias del parlamento, dentro de la tradición montesquiana de separación de poderes o funciones en cada rama del poder público.

No obstante es conveniente aclarar que el concepto originario de "legislador negativo" hoy día se encuentra ampliamente superado por la doctrina italiana y la que proviene de su Corte Constitucional así como de la española y la alemana. ${ }^{27}$

El modelo kelseniano de control concentrado tiene como efecto importante, la aplicación del principio erga omnes según el cual, las sentencias de constitucionalidad de los tribunales son aplicables a todo el mundo. Las normas inconstitucionales deben ser retiradas de la vida jurídica si se en-

25 Este postulado lo defendió en un clásico de la doctrina constitucional de comienzos del siglo XX: ¿Quién debe ser el defensor de la Constitución? En esta obra, Kelsen hace referencia al órgano que tiene por función defender la Constitución contra posibles violaciones de normas inferiores. Kelsen se enfrentó abiertamente con Carl Schmitt quien defendía su teoría del jefe de Estado como defensor de la Constitución y negaba esta función al tribunal constitucional.

${ }^{26}$ Kelsen, Hans, "La garantía jurisdiccional de la Constitución”, Escritos sobre democracia y socialismo. Madrid, 1988, p. 48.

27 Aja, Eliseo, Las tensiones entre el Tribunal Constitucional y la Europa actual, Barcelona, Ariel 1998. 
cuentran contrarias a la carta política. La anulación tiene el mismo carácter general que la creación de una ley nueva. Algunos tratadistas expresan que la demanda de inconstitucionalidad no es propiamente una "demanda" en los términos que formula la Teoría General del Proceso como pretensión de un derecho público subjetivo, sino propiamente una "iniciativa legislativa negativa". ${ }^{28}$

Kelsen propone también algunas categorías a este modelo. La primera consiste en dar un efecto temporal a las sentencias. Según su tesis, es posible mantener durante un periodo la fuerza de una ley anulada. Concibe igualmente la posibilidad de un efecto retroactivo a la decisión de inconstitucionalidad. ${ }^{29}$

Teniendo en cuenta todas las características y posibilidades enunciadas, Kelsen justifica la posibilidad dada a los tribunales constitucionales de diferir los efectos de las decisiones tomadas o explicar el alcance de las normas y decidir si ellas son aplicables o reemplazables. Los matices de las sentencias descritas por Kelsen, reflejan las dificultades de unificación de los diferentes tipos de sentencias de constitucionalidad pronunciadas por estos tribunales.

Las diferentes situaciones políticas, económicas y especialmente sociales que deben afrontar los tribunales en sus decisiones, hacen imperiosa la necesidad de aplicar la modulación de los efectos de sus providencias.

Esta técnica tuvo su origen en el siglo XIX en la Corte Suprema de Estados Unidos. Posteriormente comenzó su utilización en las decisiones judiciales de algunos tribunales europeos desde comienzos del siglo XX, aproximadamente hacia 1925.

Países como Alemania, España e Italia iniciaron esta técnica para dar un efecto especial a las sentencias de constitucionalidad. La doctrina colombiana ${ }^{30}$ y la jurisprudencia han definido muchos tipos de sentencias manipulativas:

28 Quiroga León, Aníbal, Los excesos del Tribunal Constitucional Peruano: a propósito del control concentrado de la Constitución, p. 11.

29 Kelsen, op. cit., p. 149.

30 Véase principalmente Olano García, Hernán Alejandro, "Tipología de nuestras sentencias constitucionales", Vniversitas, 2004; Solano González, Edgar, Sentencias manipulativas e interpretativas, tesis de grado, Bogotá, Universidad Externado de Colombia, 2000; Monroy Cabra, Marco Gerardo, La interpretación constitucional, Bogotá, Librería del Profesional, 2002; Martínez Caballero, Alejandro, "Tipos de sentencias en el control constitucional de las leyes: la experiencia colombiana", Revista Estudios Socio Jurídicos, Bogotá, vol. 2, núm. 1, marzo de 2000, p. 9. 
interpretativas, condicionadas, integrativas o integradoras y sustitutivas. La Corte Constitucional ha llamado a este tipo de fallos "modulación de los efectos de las sentencias".

En Colombia esta técnica de la modulación de fallos ha sido también utilizada por la Corte Suprema colombiana desde 1912 y por el Consejo de Estado colombiano desde 1947 en los casos de las acciones de inconstitucionalidad y de las acciones de nulidad por inconstitucionalidad respectivamente.

Bajo la Constitución Política de 1991, la Corte Constitucional ha acudido a la modulación o manipulación de sus decisiones con el fin de darle un efecto o alcance diferente a la norma revisada, diferente a la consecuencia prevista por el legislador colombiano.

Es por ello que se podría afirmar que una manera mediante la cual el juez ha substituido al legislador y al poder reglamentario del ejecutivo, ha sido por medio de la modulación o manipulación de las sentencias. Sin embargo, la intervención de la Corte en campos ajenos no es solamente de este método; lo ha hecho también ante la inactividad del legislador en aspectos que ella misma determina.

\section{SEgUNDA PARTE: EL GOBIERNO DE LOS JUECES EN COLOMBIA}

\section{Hacia una construcción teórica del concepto "gobierno de los jueces"}

La tesis de "el gobierno lo jueces", es decir de un gobierno sin legitimidad democrática, sin responsabilidad, sin capacidad de responder a las demandas sociales, nació en Estados Unidos de América bajo el mandato de Theodore Roosevelt en 1903, quien criticó la aplicación del denominado "darwinismo jurídico" (o prevalencia del derecho presumiblemente mas fuerte) del Tribunal Supremo Federal y condenó toda intervención legislativa de los jueces en la vida económica; el presidente censuró el nuevo rol de legislador irresponsable que los mismos jueces americanos se habían atribuido unilateralmente.

Edouard Lambert ${ }^{31}$ retomó esta idea y la desarrolló en Europa en su libro Le gouvernement des juges et la lutte contre la législation sociale aux

31 Lambert, Edouard, Le gouvernement des juges et la lutte contre la législation sociale aux Etats Unis, l'expérience américaine du contrôle judiciaire des lois, París, M.Giard\&Cie, 1921, p. 276. 
Etats Unis, l'expérience américaine du contrôle judiciaire des lois publicado en 1928 bajo la fórmula de "El gobierno de los jueces ". ${ }^{32}$

Tratadistas franceses como Michel Troper, Otto Pferman y Etienne Picard resaltan el hecho de que un tribunal, compuesto de algunas personas arbitrariamente designadas y sin responsabilidad política, a menudo nombradas por complacencia o por coyunturas políticas, que forman un cuerpo poco democrático, ejerza un poder tan decisivo y sin control.

Según Lacharrière, ${ }^{33}$ habría una usurpación del legislador por un cuerpo en el que el poder no habría sido previsto por la Constitución.

Troper ${ }^{34}$ constitucionalista francés y profesor de la Universidad de París ha afirmado que el hecho de que los jueces tomen decisiones políticas parecería una contradicción ya que los jueces no gobiernan; los jueces juzgan; los jueces se pronuncian por razones de legalidad y no de oportunidad.

Siguiendo la exposición de Troper $^{35}$ el concepto de gobierno de los jueces se reconocería de cuatro maneras:

1. Los jueces gobernarían porque disponen de una parte del Poder Legislativo, tesis propuesta por Lambert y Kelsen. Según este autor, si los jueces pueden apartar del mundo jurídico una ley, ellos también tendrían un Poder Legislativo. Serían, entonces, legisladores negativos.

2. La segunda forma se relaciona con la posibilidad de los jueces de iniciar de oficio ciertas acciones o controles como el de constitucionalidad.

3. Una tercera forma hace referencia a la posibilidad de los jueces de aplicar principios vagos. Según Eisenman, discípulo de Kelsen, "si el juez pudiera enunciar él mismo los principios aplicables, el gobierno de los jueces substituiría al gobierno de legislador". Troper explica diciendo: "si los principios son formulados de manera precisa y no vaga, y si el juez se encuentra encerrado

32 Actualmente es posible conseguir una reimpresión de 2010 realizada en Madrid por la Editorial Tecnos.

33 Lacharriere R. Opinion disidente, publicado en la revista Pouvoir, núm. 13, 1980, dedicada al Consejo Constitucional Francés, pp. 133-135.

34 Troper, Michel, "Existe-t-il un Concept de Gouvernement de Juges?", Gouvernement des Juges et Democratie, París, Publications de la Sorbonne, 2001.

35 Ibidem, p. 26. 
en su propia jurisprudencia, entonces el gobierno de los jueces no estaría aquí materializado".

4. Una cuarta posibilidad dice que existiría un gobierno de los jueces si éste fuera en contra de la voluntad del legislador. Ardant citado por Troper, dice, a propósito de la Corte Suprema americana: "Por cinco votos contra cuatro, ella puede poner en jaque la aplicación votada por representantes elegidos de la nación". Habría gobierno de los jueces porque la Corte expresaría una voluntad que va en contra de los elegidos de la nación.

Si aplicamos los parámetros expuestos por Troper para Colombia, podríamos concluir que, efectivamente, la Corte Constitucional ejerce "un gobierno de los jueces".

Como se ha expuesto, la Corte Constitucional colombiana ejerce el control de constitucionalidad y cuando estima que una norma es contraria a la Constitución, puede declararla inconstitucional; ella ejerce un rol de legislador negativo ${ }^{36}$ tal como fue definido en el numeral 1.

Pero la Corte ha ido más allá. También ejerce como legislador positivo por medio de las sentencias manipulativas, en las que el alto tribunal cambia el sentido de la ley, le agrega contenidos no previstos ni aprobados por el legislador y, en ocasiones, le imparte ordenes al Congreso para que legisle de determinada manera. ${ }^{37}$

La Corte Constitucional colombiana puede revisar de oficio ciertos decretos en ciertos casos, precisamente en los estados de excepción, las leyes estatutarias (sobre derechos fundamentales), las leyes aprobatorias de tratados internacionales y la ley de plan de desarrollo del presidente. Sería entonces el caso presentado en el numeral 2.

La Corte Constitucional revisa las sentencias de tutela y profiere fallos de revisión de constitucionalidad. Como se ha visto anteriormente, la Corte es creadora de verdaderos principios de derecho pues no se limita

36 En los términos del ya citado artículo 241 de la Constitución Política de 1991.

37 Véase, por ejemplo, las sentencias C-473/94 donde la Corte exhortó al Congreso a legislar sobre los servicios públicos esenciales, o la sentencia C-700/1999 en la que la Corte declaró contraria a la carta política, el Decreto que regulaba el sistema de financiación de vivienda (UPAC) y le ordenó al Congreso de la República tramitar una ley que reglamentara este tema. 
a aplicar exclusiva y taxativamente los principios contenidos en la Constitución. ${ }^{38}$

Además, la Corte no se encierra nunca en su propia jurisprudencia. Ella la ha modificado cuando ha estimado conveniente decidir de otra forma. Por ejemplo, en la sentencia SU 047 de 1999, la Corte cambió su propia jurisprudencia de constitucionalidad con un fallo de revisión de tutela. Estaríamos entonces en el caso de numeral 3.

En muchas ocasiones, la Corte Constitucional ha revisado demandas de constitucionalidad y las ha declarado inconstitucionales con una débil mayoría (4 vs. 5), como, por ejemplo, la polémica sentencia C-221 de 1994 sobre la despenalización de la dosis personal de droga, la cual fue decidida con estrecho margen de 5 contra 4 . Nos encontraríamos frente al caso del numeral 4.

Los críticos y algunos sectores del gobierno han atacado esta jurisdicción preguntándose: ¿Cómo pueden los jueces ir en contra del trabajo del legislador?; ¿cómo la voluntad de los representantes democráticos elegidos puede ser confrontada con la voluntad de aquellos que no son elegidos?

Las respuestas a estos interrogantes se podrían plantear desde varias perspectivas: la resistencia constitucional, la dicotomía entre interpretación e invención, la vinculación a la Escuela del derecho libre y realismo jurídico, los casos difíciles de resolver o el cambio del paradigma jurídico colombiano. A continuación se desarrollarán brevemente.

38 Sobre este punto se puede ejemplificar con el tratamiento dado por la Corte Constitucional al tema del aborto. En una primera sentencia de constitucionalidad (C-133 de 1994 MP Antonio Barrera Carbonell), el alto tribunal declaró ajustada a la carta política la penalización que consagraba el Código Penal colombiano. En un segundo, tercer y cuarto fallo sobre el mismo tema (sentencias C-013 de 1997 M.P. José Gregorio Hernández, C-647 de 2001 MP Alfredo Beltrán Sierra y C-198 de 2002 MP Clara Inés Vargas), la Corte ratificó su anterior posición. Sin embargo, en la sentencia 355 de 2006 MP Jaime Araujo Rentería y Clara Inés Vargas, la Corte despenalizó el aborto en cuatro casos especiales, bajo el argumento de que los derechos de la madre no pueden sacrificarse en favor de la protección a la vida del nasciturus. Se deduce claramente un planteamiento nuevo en términos de principios constitucionales frente a los derechos reproductivos de la mujer. Esta nueva interpretación constitucional produjo rechazo en muchos sectores conservadores y religiosos colombianos que plantean la inviolabilidad absoluta del derecho a la vida. 


\section{Posibles explicaciones al fenómeno del gobierno de los jueces}

\section{A. Primera posibilidad: "la resistencia constitucional".}

La primera posibilidad que se podría considerar sería la existencia de una "resistencia constitucional". Este término empleado por Francisco Tomás y Valiente, ${ }^{39}$ puede ser entendido como la adaptabilidad de la Constitución a la dinámica política; también como la capacidad de que la Constitución sea interpretada de forma flexible y hasta cierto punto cambiante, en función de nuevos problemas y nuevas sensibilidades o exigencias, a propósito de los derechos fundamentales en ella positivizados pero no definidos.

La resistencia significaría entonces la posibilidad de reinterpretación de la Constitución como forma de adaptación a la dinámica de la sociedad, lo que implica la inutilidad de una reforma. En este sentido, las distintas vertientes, tendencias y expectativas podrían ser posibles dentro de la Constitución; el resultado sería su duración prolongada y sin reformas.

Esta primera posibilidad podría explicar las soluciones aplicadas en muchos casos por la Corte Constitucional quien interpreta la Constitución de tal manera que responde a los problemas que a diario debe resolver sobre tópicos relacionados con derechos fundamentales y con la protección de la carta fundamental. La Constitución como conjunto de normas de gran amplitud, requiere un desarrollo de tipo legal, que en un momento dado, al no poseerla, la volvería inaplicable. Sin embargo, por mandato de la misma carta (artículo 4), esta situación no es óbice para su aplicación directa en un caso particular, especialmente en las situaciones de protección de derechos fundamentales.

Como todo tribunal, la Corte puede en algún momento cambiar su jurisprudencia y, en consecuencia, reinterpretar la Constitución, tal como lo ha efectuado en numerosas ocasiones, ya sea por el relevo de magistrados o simplemente por el cambio de los supuestos fácticos o cambios en su jurisprudencia.

39 Tomas y Valiente, Francisco, "La resistencia constitucional y los valores", cit. por Joseph Aguiló, La Constitución del Estado constitucional, Bogotá-Lima, Palestra-Temis, 2004, p. 114. 


\section{B. Segunda posibilidad: dicotomía entre interpretación e invención}

Esta segunda posibilidad ha generado numerosos debates doctrinarios en filosofía jurídica. Tal distinción y diferenciación permite establecer un límite a la discreción judicial al momento de decidir sobre un problema jurídico. Varios autores han abordado este tema, tales como Ronald Dworkin en su célebre obra El imperio de la ley, ${ }^{40}$ Marmor A. en Interpretation and legal theory o Wittgenstein en Investigaciones Filosóficas, entre muchos otros.

Al entrar a precisar el alcance del término interpretación, se podría tomar la posición de Wittgenstein, ${ }^{41}$ quien afirma que interpretar es la actividad o el proceso de sustituir una formulación de la regla por otra como algo distinguible de comprender o captar el contenido de una regla. Es decir, el juez o intérprete debe estar en condiciones de captar el contenido de una regla o especificar sus instancias de uso, pero si no le fuere posible, debe hallarle el verdadero contenido y dimensión y escoger entre las diferentes posibilidades. Alessandri Rodríguez afirma que la interpretación legal "es la determinación del significado, alcance, sentido o valor de la ley frente a las situaciones jurídicas concretas a que dicha ley debe aplicarse". Dworkin expresa que interpretar es un modo de conocer, captar o entender algo y emitir juicios verdaderos acerca de algo.

Invención es la acción o efecto de inventar, hallar o descubrir algo nuevo o desconocido. Con la interpretación el juez parte de una regla conocida y le fija su alcance para poder aplicarla a un caso, mientras que con la invención, el juez crea una regla no fijada ni establecida por el creador natural y legítimo de las normas: el legislador o el pueblo (constituyente primario). Sin embargo, puede ocurrir que el juez cree una regla a partir de otra ya conocida.

A partir de la interpretación, el juez pueda crear, como lo ha establecido en numerosas ocasiones la Corte Constitucional; pero ¿crear qué? ¿Nuevas normas? ¿O simplemente subreglas que puedan dar aplicación a las reglas contenidas en la Constitución y la ley?

Si nos se observa nuevamente hacia el aspecto funcional, la competencia del juez no sería la de crear normas; esto es obviamente tarea del legislador. Pero entonces ¿por qué el juez constitucional colombiano en ocasiones lo

40 Op.,cit., pp. 67 y 68 y 229-232.

41 Wittgenstein, L., "Investigaciones filosóficas", cit. por Maritza Iglesias Vila, El problema de la discreción judicial. Una aproximación al conocimiento jurídico, Madrid, Centro de Estudios Políticos y Constitucionales, 1999, p. 162. 
hace? Consideramos que esto puede obedecer a la ausencia de normas claras y expresas (en virtud de la generalidad de las normas constitucionales) que prevean todos lo aspectos posibles, que faciliten al operador judicial el pleno establecimiento de la solución de un caso difícil.

Esto se vio claramente en la creación de ciertas reglas específicas realizada por la Corte Constitucional en los eventos de vulneración del derecho al hábeas data, cuando aún no existía norma que regulara la materia.

Igual ocurre con el derecho de petición en asuntos pensionales, aspecto en la cual la Corte ha fijado unos plazos límites que poseen las entidades de previsión para atender las respuestas de los peticionarios. En estos casos existiría invención judicial y no interpretación.

Esta actividad creadora del juez ha sido justificada por la Corte en numerosas ocasiones, como por ejemplo en la consecución del principio de igualdad. En Sentencia C-836 de 2001 expresó:

... la Constitución garantiza la efectividad de los derechos a todas las personas y los jueces en sus decisiones determinan en gran medida su contenido y alcance frente a las diversas situaciones en las que se ven comprometidos. Por lo tanto, una decisión judicial que desconozca caprichosamente la jurisprudencia y trate de manera distinta casos previamente analizados por la jurisprudencia, so pretexto de la autonomía judicial, en realidad está desconociéndolos y omitiendo el cumplimiento de un deber constitucional. Lo dicho hasta ahora justifica la actividad creadora del juez, para que éste atribuya los criterios materiales de igualdad establecidos en la Constitución y la ley en cada caso.

Existiría interpretación en los casos de los fallos de defensa de la Constitución como en los del bloque de constitucionalidad, en los cuales la Corte interpreta diferentes artículos de la misma carta y llega a la conclusión de que un conjunto de normas que se encuentran en la misma Constitución conforman un conjunto o bloque especial de preceptos que se deben tomar como referencia al momento de juzgar la constitucionalidad de una norma.

La interpretación tiende a buscar el sentido y el alcance de la norma, principalmente cuando el operador judicial se encuentra frente a un caso difícil; cuando existe un caso fácil, no habrá lugar a interpretación sino simplemente a su aplicación. 


\section{Tercera posibilidad: vinculación a la Escuela del derecho libre y realismo jurídico. La jurisprudencia de valores}

La escuela del derecho libre y realismo jurídico se ha desarrollado en contraposición al positivismo jurídico propugnado por Hans Kelsen y posteriormente por Herberth Hart. Esta corriente propugna por un juez pensante y no un simple mecanicista aplicador de la norma; éste debe conocer los antecedentes históricos de la ley y tener en cuenta los intereses conocidos para la resolución de cada caso. El juez debe estar en capacidad de comprender el sistema axiológico que se encuentra en el sistema jurídico, lo cual le permitirá resolver en forma justa cada caso. En esta operación se denota un claro tránsito de la jurisprudencia de intereses ${ }^{42}$ a una jurisprudencia de valores. ${ }^{43}$ Los fallos judiciales entran cada vez más en aspectos sociológicos y axiológicos, teniendo el juzgador un amplio campo discrecional para fallar, dejando de lado la simple aplicación silogística y mecánica de la ley. El juez toma el papel de activo creador de reglas, lo cual le genera una enorme responsabilidad ante la sociedad.

Por su parte, Kelsen y Hart defienden el carácter parcialmente reglado de la actividad judicial a partir de una teoría del derecho y del ordenamiento.

La Escuela del derecho libre puso en evidencia la crisis de la escuela exegética del derecho y de la jurisprudencia deductiva, imperante durante todo el siglo XIX y parte del XX en la Europa occidental y un poco más allá en América.

Jürguen Habermas la ha descrito en forma muy precisa así:

Desde el punto de vista del "Legal Realism", de la Escuela del Derecho libre y de la jurisprudencia de intereses, ya no cabe establecer distinción alguna entre derecho y política recurriendo a rasgos estructurales. Pero si los procesos de decisión jurídica pueden describirse en términos similares

42 Según Heck la jurisprudencia de intereses considera que la finalidad del derecho es resolver conflictos de intereses por medio de la protección especial que confiere la ley.

43 M. J. Perry cit. por Habermas explica que en la jurisprudencia de valores, el juez no puede atenerse a la letra estricta ni depender de las convicciones mayoritarias: "interpretar" alguna provisión de la Constitución es, en lo esencial, asegurarse de su sentido aspiracional y después hacer valer ese sentido, es decir, responder a la cuestión de qué significa esa aspiración para el conflicto ante el que se está y qué es lo que esa aspiración, cuando se la acepta, exige que el tribunal haga. En Alemania, esta modalidad de jurisprudencia de valores ha tenido como problema la legitimidad de las decisiones del Tribunal constitucional alemán, ya que han puesto a competir a éste con el Poder Legislativo. 
a los procesos políticos de poder, pierde su sentido el postulado de asegurar la seguridad jurídica mediante decisiones consistentes sobre la base de un sistema de normas suficientemente determinadas. El derecho producido en el pasado pierde su dominio sobre las decisiones actuales porque éstas caen en buena medida en el ámbito de la discrecionalidad del juez. La pretensión de legitimidad del derecho puede conservar en todo caso su sentido por vía de que el juez, al igual que un político tome sus decisiones orientándose al futuro, y ello en virtud de orientaciones valorativas que él tiene por racionales. El derecho aparece entonces como un instrumento de control del comportamiento que puede utilizarse para fines políticos racionales, es decir, fundamentados en términos utilitaristas o en términos de economía de bienestar.

(...)

Una abierta revocación de la garantía de seguridad jurídica significaría que la administración de justicia habría de renunciar en última instancia a cumplir la función del derecho de estabilizar expectativas de comportamiento. ${ }^{44}$

La aplicación de las tesis de esta Escuela presentan ciertos riesgos especialmente para la sociedad democrática, ya que los ciudadanos quedan sometidos completamente a las decisiones de los jueces, las cuales pueden ser demasiado cambiantes y pueden alejarse de la uniformidad con fundamento en el carácter discrecional de ésta. Es decir, se puede desencadenar una arbitrariedad judicial debido a las diferentes concepciones y apreciación de lo que es "lo justo".

La historia alemana, específicamente de la época del ascenso del nazismo, demuestra los riesgos de la aplicación de dicha escuela. El gobierno nazi asimiló estos postulados de la escuela del derecho libre y obligó a los jueces a fallar de determinada forma, apartándose del sentido literal y accediendo al sentido de justicia del régimen, logrando suprimir las incómodas limitaciones de la Constitución de Weimar. ${ }^{45}$

Esta Escuela encajó perfectamente en el sistema norteamericano donde impera una tradición jurídica especial: el common law o derecho elaborado por los jueces.

${ }^{44}$ Habermas, Jürguen, Facticidad y validez. Sobre el derecho y el Estado democrático de derecho en términos de teoría del discurso, Madrid, Editorial Trotta, 2000, p. 270.

45 Prieto Sanchís, Luis, Ideología jurídica e interpretación jurídica, Madrid, Technos, 1987, capítulos 1 y 2 . 
Ya en Colombia, la jurisprudencia elaborada por la Corte Constitucional guarda bastante cercanía con los postulados de la Escuela del derecho libre y realismo jurídico y con la jurisprudencia de valores. En efecto, la Corte ha puntualizado que la importancia de la literalidad de la norma debe ceder ante la obtención del valor justicia en los fallos de los jueces. El operador judicial ha dejado de ser un pasivo aplicador mecánico de la norma para pasas a ser un creador de derecho.

En casos relacionados con acciones de tutela, la Corte ha proyectado su misión protectora de derechos fundamentales, en aspectos que van más allá de la aplicación de una norma fundamental que ordena determinada protección; al prescribir soluciones ante análisis y valoraciones de tipo sociológico y humano. Tal es el caso de la protección de los derechos de los reclusos de las cárceles, que ha efectuado la Corte mediante la creación del Estado de cosas inconstitucional, o en el análisis sociológico y ético que efectuó el tribunal constitucional en el caso de la despenalización de la dosis personal de droga.

\section{Cuarta posibilidad: los casos dificiles de resolver}

Un caso es considerado difícil cuando los hechos y las normas importantes permiten más de una solución. Un caso es fácil cuando su solución no produce problemas, porque la norma permite ser aplicada sin ningún problema de interpretación. Es posible hacer un silogismo con el problema:

- Previsión normativa

- Problema a resolver

- Solución

El caso difícil más corriente es aquel en el cual existe una norma de tipo abierto, lo que permite más de una interpretación y además de ello, puede contener significaciones imprecisas. Cuando existe más de una posibilidad de solución a un problema, es al juez a quien corresponde decidir.

De cara a esta situación, ¿cuál es el camino que puede tomar la Corte Constitucional? En primer lugar, ella trata de aplicar la Constitución pero si la carta no da respuestas, la Corte elabora su propia solución con construcciones iusfilosóficas y en ocasiones morales. 
Por ejemplo, en la sentencia C-546 de 1992, la Corte dijo:

Por eso, la Constitución efectiva de un Estado no se limita a la simple enumeración de sus artículos. La carta debe ser complementada con las decisiones judiciales que indican la manera como se aplican sus normas. Dicho en otras palabras: el juez constitucional, en sus decisiones, complementa el texto legal con los criterios de aplicación, esto es, con las excepciones a la regla que no han sido contempladas en el texto fundamental, a través de la creación de las normas que la doctrina ha denominado "sub-constitucionales".

El texto transcrito demuestra la clara influencia de las nuevas teorías del derecho propugnadas por los teóricos de la filosofía. Por ejemplo, Hart expresa que el derecho de un Estado no se encuentra únicamente en los textos normativos creados por el legislador como representante legítimo del pueblo; el derecho se encuentra en la construcción de conceptos y de ideas que los jueces y magistrados tienen hoy. ${ }^{46}$

Como las nuevas tendencias del derecho entregan la gran responsabilidad al juez para crear el derecho, este proceso intelectual del funcionario judicial se ve necesariamente influenciado por aspectos exógenos a la simple aplicación mecánica de la norma.

Una Constitución política, al ser una norma general, necesariamente tendrá lagunas y vacíos que el aperador judicial deberá llenar al momento de efectuar su aplicación. Esos vacíos son llenados por el juez mediante el empleo de una serie de principios y de reglas, que la misma Corte Constitucional ha desarrollado. Es por ello que el campo de acción del alto tribunal es muy amplio.

Generalmente las normas y reglas no contienen un resultado único. Las reglas contienen hipótesis que, en ciertas situaciones, no prevén todas las posibilidades. En esos casos, el juez constitucional debe crear el derecho.

Esta tendencia contemporánea ha sido expuesta por Luis Recasens Siches, teórico de la filosofía del derecho, quien en su obra La nueva filosofía de interpretación del derecho dijo:

No es exagerado afirmar que en casi la totalidad del pensamiento jurídico contemporáneo, la concepción mecánica de la función judicial comprendida como un silogismo, ha caído en descrédito.

(...)

${ }^{46}$ Hart, op. cit., pp. 125 y ss. 
... las diversas críticas contra la concepción mecánica de la jurisprudencia han demostrado que la acción del juez o del órgano judicial administrativo, contienen siempre una función creadora del derecho. ${ }^{47}$

Se podría entonces afirmar que la Corte Constitucional colombiana es una exponente de esta tendencia. En efecto, desde sus comienzos, el alto tribunal ha afirmado que en un Estado constitucional de derecho, la función del juez constitucional no debe limitarse a la de ser un aplicador mecánico del derecho. Él debe ser un creador de la norma, aún en detrimento de la seguridad jurídica. ${ }^{48}$

De esta conclusión surgiría otra pregunta: ¿Cuál es el límite a este poder casi ilimitado de los jueces? Según Hart, el límite está en los textos de las normas y en la jurisprudencia ${ }^{49}$.

\section{E. El cambio del paradigma jurídico colombiano}

Los diferentes sistemas jurídicos del mundo presentan concreciones y variaciones muy particulares que los hacen únicos a pesar de su vinculación a sistemas jurídicos genéricos; es decir, cada sistema tiene su propio paradigma.

Según Habermas, un paradigma jurídico determinado explica, con ayuda de un modelo de la sociedad contemporánea, de qué modo se deben comprender y orientar los principios del Estado de derecho y los derechos fundamentales para que puedan cumplir en un determinado contexto, las funciones que le son asignadas por ley.

Por ejemplo, en el paradigma del Estado democrático de derecho, la legislación política se considera como la materialización de este paradigma; o en el modelo social del derecho, el paradigma jurídico indica cómo pueden entenderse y realizarse los derechos fundamentales y los principios del Estado de derecho.

Habermas afirma que los dos paradigmas jurídicos que más consecuencias han tenido en la historia del derecho moderno y que aún hoy siguen compitiendo entre sí son el de derecho formal burgués y el del derecho materializado en términos de Estado social.

47 Recaséns Siches, Luis, Nueva filosofia de interpretación del derecho, México, Porrúa, 1973, pp. 211 y ss.

48 Corte Constitucional, Sentencia T-406/92 M.P. Ciro Angarita Barón.

49 Hart, op.cit., p. 164. 
En el caso colombiano, consideramos que el viejo paradigma sobre el cual se cimentó el Estado decimonónico fue el del imperio de la ley. Generaciones de abogados, funcionarios judiciales, magistrados y juristas crecieron y se formaron como tales con las fundamentaciones teóricas que imponía este modelo: estricta división tripartita de poderes al más puro estilo de Montesquieu, pero con un Poder Ejecutivo fuerte, tipo cuasi-imperial, seguridad jurídica, infalibilidad de la ley y del legislador, estricta observancia del aforismo latino lex dura sed lex, teorización de los derechos fundamentales pero sin mecanismos para su protección, etcétera.

Con la llegada de la Constitución de 1991 y el desarrollo jurisprudencial efectuado por la Corte en materia de derechos fundamentales y defensa de la carta, este viejo paradigma cambió.

Ahora la estricta división de poderes o funciones del Estado viene aparejada con una mutua cooperación pero con independencia y autonomía de cada una de ellas; el ejecutivo ha perdido su gran poderío y la rama judicial ha entrado a jugar un papel protagónico en el nuevo esquema; la seguridad jurídica ha tenido que ceder ante los principios básicos de igualdad y justicia; el legislador ha debido someterse a los parámetros establecidos por la Constitución y su intérprete oficial, la Corte Constitucional; el imperio de la ley ha caído y hemos entrado en el imperio de la Constitución, la cual tiene aplicación directa sin necesidad de una ley regulatoria, específicamente en temas de derechos fundamentales.

Es decir, el Estado colombiano ha cambiado su paradigma del imperio de la ley y de la escuela de la exégesis, por el del imperio de la Constitución, de los derechos fundamentales, de los principios y valores y del poder de la jurisdicción constitucional encabezada por la Corte Constitucional.

Consideramos que esto se ha venido dando principalmente por los desarrollos jurisprudenciales de la Corte Constitucional, impulsada por una nueva casta de magistrados imbuidos en las nuevas teorías de la filosofía del derecho y especialmente por las teorías críticas; la influencia de teóricos como Rawls, Hart, Dworkin, Habermas y muchos más, deja ver claramente el peso de estas nuevas tendencias importadas a Colombia, principalmente por el contacto internacional de los nuevos abogados y magistrados de la Corte; en efecto, una gran mayoría de ellos han efectuado estudios de postgrado en escuelas francesas, norteamericanas y últimamente españolas, lo que ha permitido mirar más de cerca la evolución de estas nuevas corrientes y aplicarlas a este medio.

Fecha de recepción: 3 de septiembre de 2010.

Fecha de dictamen: 30 de septiembre de 2010. 